\title{
Article
}

\section{Acid Stripping after Infection Improves the Detection of Viral HLA Class I Natural Ligands Identified by Mass Spectrometry}

\author{
Elena Lorente ${ }^{1}$, Miguel Marcilla ${ }^{2}$, Patricia G. de la Sota ${ }^{1}{ }^{\circledR}$, Adriana Quijada-Freire ${ }^{1}$, Carmen Mir ${ }^{1}$ \\ and Daniel López ${ }^{1, *(D)}$ \\ 1 Centro Nacional de Microbiología, Instituto de Salud Carlos III, 28220 Majadahonda, Spain; \\ elorente@isciii.es (E.L.); patric15@ucm.es (P.G.d.1.S.); aquijada@cnb.csic.es (A.Q.-F.); \\ carmen.mir@isciii.es (C.M.) \\ 2 Proteomics Unit, Spanish National Biotechnology Center (CNB-CSIC), 28049 Madrid, Spain; \\ mmarcilla@cnb.csic.es \\ * Correspondence: dlopez@isciii.es; Tel.: +34-918223708
}

check for updates

Citation: Lorente, E.; Marcilla, M.; de la Sota, P.G.; Quijada-Freire, A.; Mir, C.; López, D. Acid Stripping after Infection Improves the Detection of Viral HLA Class I Natural Ligands Identified by Mass Spectrometry. Int J. Mol. Sci. 2021, 22, 10503. https:// doi.org/10.3390/ijms221910503

Academic Editors: Radoslaw M. Sobota and Alexande Baykov

Received: 9 August 2021

Accepted: 26 September 2021

Published: 29 September 2021

Publisher's Note: MDPI stays neutral with regard to jurisdictional claims in published maps and institutional affiliations.

Copyright: (c) 2021 by the authors. Licensee MDPI, Basel, Switzerland. This article is an open access article distributed under the terms and conditions of the Creative Commons Attribution (CC BY) license (https:// creativecommons.org/licenses/by/ $4.0 /)$.

\begin{abstract}
Identification of a natural human leukocyte antigen (HLA) ligandome is a key element to understand the cellular immune response. Advanced high throughput mass spectrometry analyses identify a relevant, but not complete, fraction of the many tens of thousands of self-peptides generated by antigen processing in live cells. In infected cells, in addition to this complex HLA ligandome, a minority of peptides from degradation of the few proteins encoded by the viral genome are also bound to HLA class I molecules. In this study, the standard immunopeptidomics strategy was modified to include the classical acid stripping treatment after virus infection to enrich the HLA ligandome in virus ligands. Complexes of HLA-B*27:05-bound peptide pools were isolated from vaccinia virus (VACV)-infected cells treated with acid stripping after virus infection. The HLA class I ligandome was identified using high throughput mass spectrometry analyses, yielding 37 and 51 natural peptides processed and presented untreated and after acid stripping treatment VACVinfected human cells, respectively. Most of these virus ligands were identified in both conditions, but exclusive VACV ligands detected by mass spectrometry detected on acid stripping treatment doubled the number of those identified in the untreated VACV-infected condition. Theoretical binding affinity prediction of the VACV HLA-B*27:05 ligands and acute antiviral T cell response characterization in the HLA transgenic mice model showed no differences between HLA ligands identified under the two conditions: untreated and under acid stripping condition. These findings indicated that acid stripping treatment could be useful to identify HLA class I ligands from virus-infected cells.
\end{abstract}

Keywords: HLA class I; immunoproteomics; ligand; peptide; virus

\section{Introduction}

Proteasomes and other cytosolic peptidases degrade self and pathogenic proteins, generating an extremely varied pool of peptides, both in sequence and in length. Some of these degradation products are translocated to the endoplasmic reticulum (ER) lumen by the transporter associated with antigen-processing (TAP) molecules [1]. The peptides with the correct length (8 to 12 residues) and strong interactions with specific residues of the antigen recognition site of the HLA class I molecule [2], usually at position 2 (P2) as an anchor residue motif and auxiliary amino acids at the C-terminus [3,4], can stabilize their binding to HLA class I molecules. Amino-terminally extended precursors can be also utilized for antigen presentation, generally (but not exclusively) after precursor trimming by ER-resident aminopeptidase activities [5-7]. The specific interaction of peptide with the HLA class I molecule in the ER stabilizes the nascent trimolecular peptide-HLA- $\beta_{2}-$ microglobulin complexes and allows for their subsequent export to the cell membrane, where they can interact with the CD8 receptor [8]. The recognition of foreign or self-peptide 
ligands can lead to the beneficial killing of pathogen-infected cells or, instead, to initiate an autoimmune damage, respectively.

Advanced high throughput mass spectrometry has contributed significantly to identify virus-derived natural ligands presented by HLA molecules, a key element to understand the cellular antiviral immune responses [9]. These massive analyses can resolve the sequence of several thousand HLA-bound peptides for each experiment. However, the hundreds of thousands of HLA class I molecules expressed on the surface of a cell [10] can bind many tens of thousands of peptides in different amounts. In infected cells, additional to this complex self HLA ligandome, the peptides generated by the antigen processing of the dozens or few hundred of viral proteins encoded by the pathogen genome are also presented in the cell surface bound to the HLA class I molecules. In the determination of targets of cellular immune response, these self-peptides are not only irrelevant but also obstruct the identification of pathogen-derived ligands due to their extreme diversity and abundance. Thus, methods that increase the virus/self ratio of the HLA class I ligands analyzed by mass spectrometry would be highly desirable. In this context, the depletion of cell surface HLA class I molecules after virus infection by the classical acid stripping treatment [11] carried out in this study improved the identification of vaccinia virus (VACV) ligands detected by mass spectrometry.

\section{Results}

\subsection{Physiological Processing Generated Different Viral HLA-B*27:05 Ligands in Human VACV-Infected Cells}

The HLA-B*27:05-bound peptide pools were isolated from large numbers of aciduntreated and either uninfected or VACV-infected cells. These peptide mixtures were subsequently separated by reversed-phase HPLC and were analyzed by LC-MS/MS. By means of bioinformatics tools, different fragmentation spectra detected in the VACV-infected HLAbound peptide pools (but absent from both control uninfected pools), corresponded, with high confidence, to VACV-derived peptides (Table 1). Additionally, a human proteome database search failed to identify any of these spectra as human protein fragments, supporting the viral origin of these ligands. Eighteen different VACV proteins (3BHS, A31, B18, C10, D2, E8, F7, F11, F12, F17, I1, K1, MCE, RP19, RP22, RP35, VGF, and VLTF1) displayed individual ligands bound to HLA-B*27:05 molecules (Table 1 ). In addition, another five VACV proteins (B25, C13, H3, RP132, and VITF3) yielded two HLA-B*27:05 ligands each (Table 1). Moreover, three different viral ligands from B1 protein were identified bound to HLA-B*27:05 molecules (Table 1). Finally, the VACV E5 protein also generated six HLA$B * 27: 05$ ligands. (Table 1). Therefore, these results indicate that a total of 37 HLA-B*27:05 ligands from 28 different VACV proteins were processed and presented in VACV-infected human cells.

Table 1. Summary of the HLA-B*27:05 ligands detected by MS/MS analysis in VACV-infected cells.

\begin{tabular}{|c|c|c|c|c|c|c|c|}
\hline Peptide & $\begin{array}{c}\text { Experimental } \\
\text { Mass }\end{array}$ & Length & Protein & Position & Accession & $\begin{array}{l}\text { Untreated } \\
\text { Cells }{ }^{\text {a }}\end{array}$ & $\begin{array}{l}\text { Stripping } \\
\text { Condition }^{\text {a }}\end{array}$ \\
\hline GRYIVKLLI & 1073.696 & 9 & 3BHS & $14-22$ & P26670 & 1 & 1 \\
\hline KRNDEVLFR & 1175.6411 & 9 & $\mathrm{~A} 27$ & 99-107 & P11258 & ND & 2 \\
\hline LRFLEKTSF $^{b}$ & 1139.6338 & 9 & A31 & $8-16$ & P24760 & 2 & ND \\
\hline YRHVPILGR & 1109.6458 & 9 & A 32 & $206-214$ & P68615 & ND & 2 \\
\hline GRIDNINMSI & 1147.5656 & 10 & A37 & $254-263$ & P24762 & ND & 2 \\
\hline GRLFNEIKKF & 1250.7135 & 10 & A52 & $77-86$ & Q01220 & ND & 2 \\
\hline YRFLVINR & 1079.624 & 8 & B1 & $103-110$ & P16913 & 1 & 1 \\
\hline YRFLVINRL & 1192.708 & 9 & B1 & $103-111$ & P16913 & 1 & 1 \\
\hline RRGDLETLGY & 1178.6044 & 10 & B1 & $210-219$ & P16913 & ND & 2 \\
\hline IRWLGGILPWTK & 1438.8448 & 12 & B1 & $229-240$ & P16913 & 2 & 2 \\
\hline VRIKNDIVVSR & 1297.783 & 11 & B18 & $232-242$ & P25213 & 2 & 3 \\
\hline TRFNPSVLK & 1060.6029 & 9 & B25 & 111-119 & Q805H0 & 3 & 3 \\
\hline TRFNPSVLKILLH & 1536.9139 & 13 & B25 & $111-123$ & Q805H0 & 3 & 3 \\
\hline$\underline{\text { IRNDIRELF }}$ & 1174.6458 & 9 & $\mathrm{C} 10$ & $22-30$ & P03296 & ND & 2 \\
\hline
\end{tabular}


Table 1. Cont.

\begin{tabular}{|c|c|c|c|c|c|c|c|}
\hline Peptide & $\begin{array}{c}\text { Experimental } \\
\text { Mass }\end{array}$ & Length & Protein & Position & Accession & $\begin{array}{l}\text { Untreated } \\
\text { Cells }^{a}\end{array}$ & $\begin{array}{l}\text { Stripping } \\
\text { Condition }\end{array}$ \\
\hline TRFYFNMPK & 1202.5906 & 9 & $\mathrm{C} 10$ & $323-331$ & P03296 & 3 & 3 \\
\hline SRFTIGRALF & 1166.656 & 10 & $\mathrm{C} 13$ & $90-99$ & P17365 & 1 & 2 \\
\hline$\underline{\text { SRFTIGRALFK }}$ & 1294.751 & 11 & $\mathrm{C} 13$ & 90-100 & P17365 & 2 & ND \\
\hline$\overline{\text { ARFDNKSIYR }}$ & 1268.6625 & 10 & $\mathrm{D} 2$ & $63-72$ & P04300 & ND & 3 \\
\hline ARFDNKSIYRI & 1381.7466 & 11 & D2 & $63-73$ & P04300 & 1 & ND \\
\hline FRVSTKLLRF & 1265.7607 & 10 & D9 & $69-78$ & P04311 & ND & 2 \\
\hline GRFGYVPYVGY & 1276.624 & 11 & D13 & $107-117$ & P68440 & ND & 2 \\
\hline$\overline{\text { GRIAPRSGL }}$ & 925.5457 & 9 & DUT & $64-72$ & P17374 & ND & 2 \\
\hline GRIAPRSGLSL & 1125.6617 & 11 & DUT & $64-74$ & P17374 & ND & 2 \\
\hline$\overline{\text { SRNPSKMVY }}$ & 1096.5336 & 9 & E5 & $130-138$ & P21606 & ND & 3 \\
\hline IRILVEERF & 1173.6869 & 9 & E5 & $179-187$ & P21606 & 3 & 3 \\
\hline IRILVEERFY & 1336.7502 & 10 & E5 & 179-188 & P21606 & 3 & 3 \\
\hline WRIIGTQVDK & 1214.6771 & 10 & E5 & 197-206 & P21606 & 3 & 3 \\
\hline ARYNLKPMYR & 1310.6918 & 10 & E5 & $219-228$ & P21606 & 2 & 2 \\
\hline YRYDDDVENGF & 1391.563 & 11 & E5 & $274-284$ & P21606 & 3 & 3 \\
\hline YRYDDDVENGFIGL & 1674.7526 & 14 & E5 & $274-287$ & P21606 & 3 & 2 \\
\hline KRFDELDINNSY & 1512.7208 & 12 & E6 & $372-383$ & P21607 & ND & 2 \\
\hline SRGLSRPLM & 1015.5597 & 9 & E8 & $27-35$ & P23372 & 2 & ND \\
\hline VRTIIDENR & 1114.6095 & 9 & ETF1 & $31-39$ & P04308 & ND & 2 \\
\hline SRFKKVYIL & 1152.7019 & 9 & ETF1 & $63-71$ & P04308 & ND & 1 \\
\hline GRSIRKFSY & 1112.609 & 9 & ETF1 & $453-461$ & P04308 & ND & 2 \\
\hline YRQQLELAY & 1182.6033 & 9 & F11 & $247-255$ & Q80HX7 & 2 & ND \\
\hline TRTIILVGY & 1034.6124 & 9 & F12 & $275-283$ & Q80HX6 & 3 & 3 \\
\hline MRTDMLQNM & 1138.4934 & 9 & F17 & $79-87$ & P07396 & 2 & ND \\
\hline A ANRDNVASRLLN & 1412.7484 & 13 & F17 & 89-101 & P07396 & ND & 2 \\
\hline FAANRDNVASRLLN & 1559.8168 & 14 & F17 & 88-101 & P07396 & ND & 1 \\
\hline ARVEFGPLYM & 1181.5903 & 10 & F7 & $57-66$ & P24359 & 2 & ND \\
\hline YRHTIESVYF & 1313.6404 & 10 & F7 & $83-92$ & P24359 & ND & 3 \\
\hline KRFTHTTAFF & 1254.6509 & 10 & G7 & 99-108 & P68716 & ND & 3 \\
\hline PVIDRLPSETFPNVH & 1719.8944 & 15 & H3 & $12-26$ & P07240 & 3 & ND \\
\hline ARIENEMKINR & 1372.7245 & 11 & H3 & $217-227$ & P07240 & 2 & ND \\
\hline KRYPGVMYAF & 1230.6219 & 10 & H3 & $266-275$ & P07240 & ND & 2 \\
\hline$\underline{\text { ARSDLSDLKV }}$ & 1102.5981 & 10 & H5 & $144-153$ & P07242 & ND & 2 \\
\hline VRIPVDLVK & 1037.6597 & 9 & I1 & $51-59$ & P16714 & 2 & 3 \\
\hline KRSATQFNF & 1097.5618 & 9 & I1 & $136-144$ & P16714 & ND & 3 \\
\hline$\overline{\text { TRLYDYFTR }}$ & 1233.6141 & 9 & I1 & $210-218$ & P16714 & ND & 3 \\
\hline SQFDDKGNTAL & 1194.5516 & 11 & K1 & $88-98$ & P04297 & 1 & 1 \\
\hline VRNKVVVNF & 1073.6345 & 9 & MCE & $258-266$ & P07617 & 2 & ND \\
\hline$\overline{\text { GRVPSVNEY }}$ & 1019.5036 & 9 & PAP1 & 23-31 & P23371 & ND & 2 \\
\hline ARDEPVFVK & 1059.5713 & 9 & RAP94 & $292-300$ & P68438 & ND & 3 \\
\hline GRLPLVSEF & 1016.5654 & 9 & RP19 & $96-104$ & P68611 & 3 & 3 \\
\hline ARDPYAVINR & 1173.6254 & 10 & RP22 & $20-29$ & P68609 & 1 & 3 \\
\hline HRFDMTKVDVELFIK & 1876.9869 & 15 & RP35 & $275-289$ & P24757 & 1 & 1 \\
\hline SRVSLEFIR & 1105.6244 & 9 & RP132 & $241-249$ & Q76ZP7 & 2 & 1 \\
\hline SRVSLEFIRR & 1261.7255 & 10 & RP132 & $241-250$ & Q76ZP7 & ND & 2 \\
\hline KRITESITDF & 1208.64 & 10 & RP132 & $272-281$ & Q76ZP7 & 1 & 2 \\
\hline GRYSAVFKDSFLR & 1544.8099 & 13 & SPI2 & $70-82$ & P15059 & ND & 2 \\
\hline RRTKLPIQDM & 1256.7023 & 10 & VGF & $128-137$ & P01136 & 2 & ND \\
\hline$\overline{\text { ARTIFNFHLI }}$ & 1230.6873 & 10 & VITF3 & $16-25$ & Q80HV2 & 3 & ND \\
\hline SRTVEIFER & 1135.5985 & 9 & VITF3 & $106-114$ & Q80HV2 & 3 & ND \\
\hline IRIKIDKLR & 1153.7659 & 9 & VLTF1 & $18-26$ & P68613 & 1 & ND \\
\hline
\end{tabular}

a Number of mass spectrometry runs from untreated or acid stripping conditions in which each peptide was detected. ND: not detected.

${ }^{\mathrm{b}}$ Underlined indicates peptides analyzed by ELISPOT. 
2.2. Diverse Viral HLA-B*27:05 Ligands Were Physiological Generated in Human VACV-Infected Cells Treated with Acid Stripping

Similar to previous conditions, the HLA-B*27:05-bound peptide pools were isolated from either uninfected or VACV-infected cells treated with acid stripping after virus infection. Different fragmentation spectra present in the HLA-B*27:05-bound peptide pools, but absent in the uninfected pools, were also matched to VACV-derived peptide sequences (Table 1). As previously, a human proteome database search failed to identify any of these spectra as human protein fragments, supporting the viral origin of these ligands. Twenty two different VACV proteins (3BHS, A27, A32, A37, A52, B18, C13, D2, D9, D13, E6, F7, F12, G7, H3, H5, K1, PAP1, RP19, RP22, RP35, and SPI2) displayed individual ligands bound to HLA-B*27:05 molecules (Table 1). In addition, the B25, C10, DUT, and F17 proteins yielded two HLA-B*27:05 ligands each (Table 1). Moreover, three different viral ligands from EFT1, I1, and RP132 proteins were identified bound to HLA-B*27:05 molecules (Table 1). Finally, VACV B1, and E5 proteins were the main contributors to antigen processing and presentation with 4 and 7 ligands bound to HLA-B*27:05 molecules (Table 1). Therefore, the immunoproteomic analysis identified a total of 51 HLA-B*27:05 ligands from 32 different VACV proteins found in VACV-infected human cells after acid stripping of infected cells.

\subsection{Most of Viral HLA-B*27:05 Ligands Were Independent of Acid Stripping Treatment}

A total of 37 and 51 VACV HLA-B*27:05 ligands were identified in untreated cells and after acid stripping VACV-infected human cells, respectively (Table 1). Twenty three of these virus ligands were identified in both conditions; 14 peptides were exclusively identified in untreated VACV-infected human cells and another 28 ligands were bound to HLA-B*27:05 in VACV-infected human cells after acid stripping (Table 1 and Figure 1A). Thus, a relevant fraction of VACV ligands detected by mass spectrometry was identified in the acid stripping treatment and this condition allowed the identification of twofold more exclusive viral ligands that the untreated VACV-infected condition. In contrast to viral ligands, about $20 \%$ more self-ligands were identified in untreated VACV-infected conditions versus the virus-infected cells after acid stripping treatment (Figure 1B).

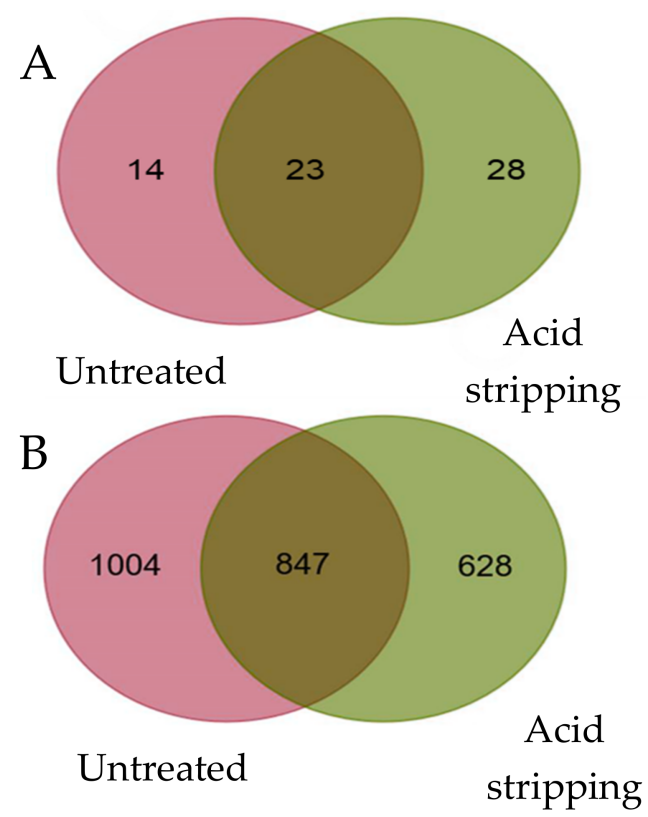

Figure 1. Overlap of HLA-B*27:05 viral and cell ligands from untreated and acid stripping condition VACV-infected cells. Venn diagram showing number de viral (A) or cell (B) ligands identified exclusively in untreated virus-infected cells (pink), acid stripping condition (green) VACV-infected cells and overlapping peptides between both conditions. 


\subsection{Theoretical Binding Affinity of the VACV HLA-B*27:05 Ligands}

Prediction of HLA peptide binding by bioinformatics software is routinely utilized to select potential candidates for viral ligands and/or to determinate the binding affinity of experimentally detected HLA ligands. Therefore, prediction of the peptide binding of the $65 \mathrm{VACV}$ ligands to the HLA-B*27:05 class I molecule was analyzed using the NetMHCIpan neural network-based alignment method. The 13 peptides exclusively associated with untreated VACV-infected cells, the 23 ligands only identified with the acid stripping treatment, and 25 of the 29 virus peptides identified in both conditions were predicted as high affinity ligands for HLA-B*27:05 binding (black dots, Figure 2). The SQFDDKGNTAL peptide was predicted by the bioinformatics tool as a low affinity ligand (red dot, Figure 2), while peptides AANRDNVASRLLN, FAANRDNVASRLLN, and PVIDRLPSETFPNVH were not predicted as HLA-B*27:05 ligands (green dots, Figure 2). Additionally, no statistical differences were observed between HLA ligands identified under the two conditions: untreated and in acid stripping condition (Figure 2).

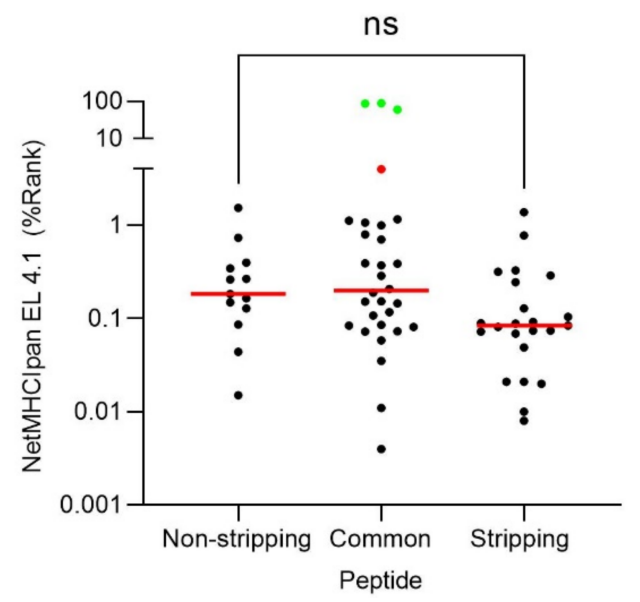

Figure 2. Theoretical binding affinity of the VACV HLA-B*27:05 ligands identified by mass spectrometry. The theoretical binding affinity to the HLA-B*27:05 class I molecule of the different VACV ligands (classified by exclusives for untreated or acid stripping conditions, as well as peptides identified in these two conditions or common peptides) was calculated with the NetMHCIpan EL 4.1 server. The threshold for strong binding peptides (marked as black dots) was 2 of the percentile rank. One peptide (marked as red dot) ranked as weak binding. In addition, another 3 peptides (marked as green dots) showed no theoretical affinity for HLA-B*27:05.

2.5. Immunogenicity of VACV-Derived Peptides Obtained after Acid Stripping in HLA-B*27:05 Transgenic Mice

Although the VACV ligands exclusively associated with the acid stripping condition showed similar characteristics of sequence (Table 1 ) and theoretical binding affinity (Figure 2) to the other HLA-B*27:05 ligands identified in the current study, it could be that these ligands were only expressed after removing cell peptides previously bound to the HLA-B*27:05 class I molecules. To analyze this point, HLA-B*27:05 transgenic mice were infected with VACV. Later, a physiological measurement of the functional ex vivo activity of $T$ cells against different HLA-B ${ }^{*}$ 27:05 viral ligands (5 exclusively identified of untreated and other 5 after acid stripping condition VACV-infected cells, underlined in Table 1) identified using mass spectrometry was carried out. Spleen cells that specifically recognized target cells that were pulsed with F17 $79-87$ (MRTDMLQNM) and C13 $90-100$ (SRFTIGRALFK) peptides (but not the other 3 ) from an untreated condition were simultaneously recognized as part of the acute response to VACV (Figure 3). The $\mathrm{C}_{10} 0_{22-30}$

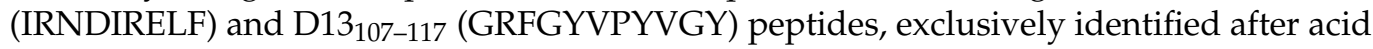
stripping treatment, displayed IFN- $\gamma^{+}$responses of the same order as F17 $79-87$ and C13 $90-100$ peptides, respectively (Figure 3). In addition, the $\mathrm{H}_{144-153}$ (ARSDLSDLKV) peptide, also associated to HLA-B*27:05 only after acid stripping treatment, was the epitope and was 
more immunogenic in the HLA-B*27:05 transgenic mice model (Figure 3). The other two peptides from acid stripping condition were not recognized by $\mathrm{T}$ cells. These data indicate that VACV ligands, identified after acid stripping condition, are also physiologically presented in the absence of this treatment, generating potent $T$ cell responses in HLA-B*27:05 transgenic mice.

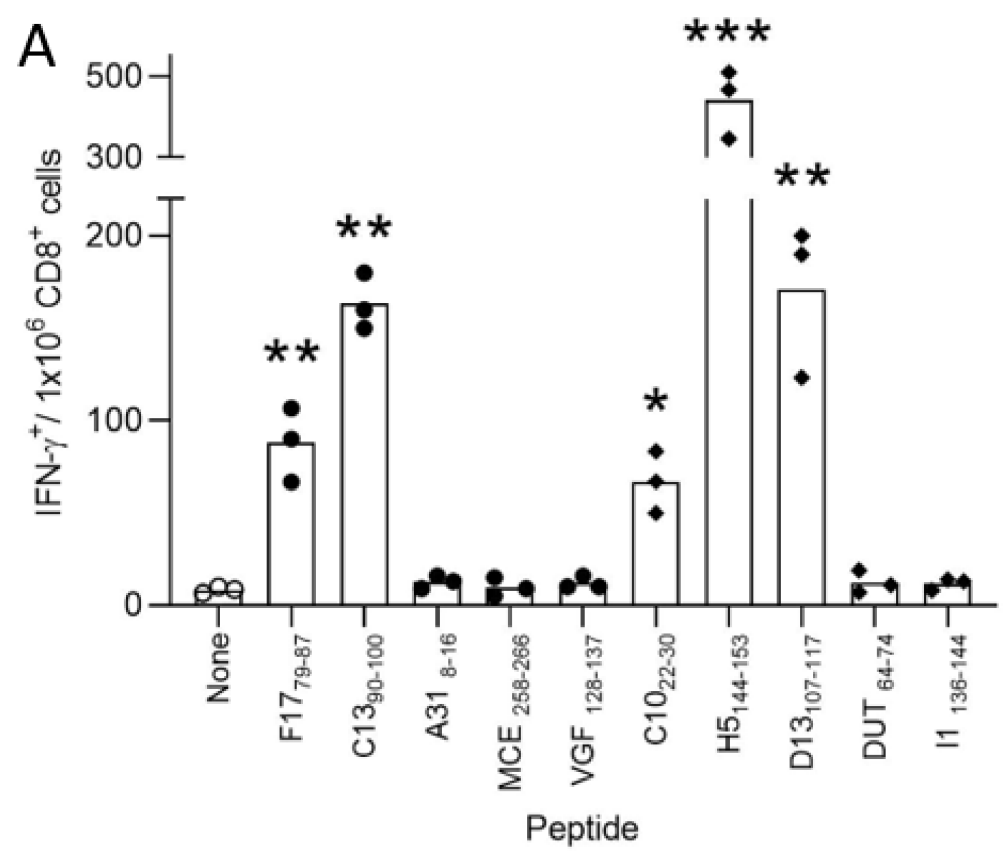

B
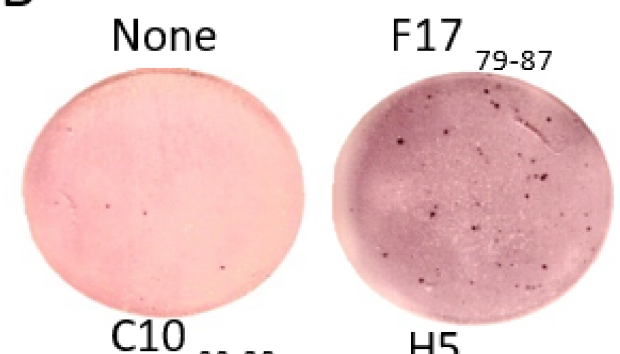

C13
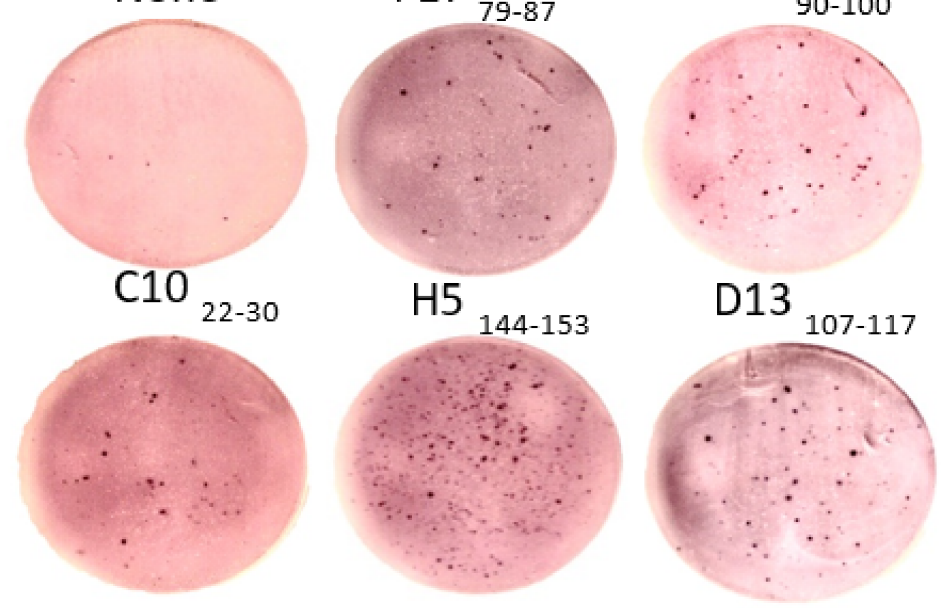

Figure 3. The immunogenicity of VACV-derived HLA-B*27:05-restricted peptides in the HLA class I transgenic mice. (A) HLA-B*27:05 target cells that were pre-pulsed with the indicated VACV-synthetic peptides and were analyzed by ELISPOT for $\mathrm{CD}^{+} \mathrm{T}$ cell activation with VACV-specific splenocytes obtained from HLA-B*27:05 transgenic mice immunized for 7 days (acute response) post VACV infection. The results are calculated as the mean of three independent experiments \pm SD. Significant $p$ values $\left(*<0.05 ;{ }^{* *}<0.01\right.$; and $\left.{ }^{* *}<0.05\right)$ of ligands exclusively identified in untreated (closed circles) or after acid stripping condition (closed diamonds) versus negative control (open circles) is indicated. A representative experiment is depicted in $(\mathbf{B})$.

\section{Discussion}

Classically, the identification of virus-derived ligands presented by HLA molecules has been addressed using partially overlapping synthetic peptides covering the fractional or full sequence of known or hypothesized antigenic proteins, or even the whole proteome when 
the virus is small enough [12]. The development of high throughput mass spectrometry has contributed to a better understanding of the cellular antiviral immune response with two main advantages over this previous experimental approach. First, the mass spectrometry analyses allow the unbiased characterization of natural ligands bound to HLA molecules in the surface of the infected cells and thus exposed to T cell activity. Second, for large-genome viruses, such as the vaccinia virus (VACV), which encodes complex proteomes of more than 200 proteins, classical overlapping synthetic peptide analyses are both very expensive and technically unfeasible in practice. However, in the mass spectrometry approach there is a problem. In the surface of the infected cell, together with occasional viral ligands, tens or even hundreds of thousands of peptides of cellular origin are also being presented by HLA class I molecules. This self-derived HLA peptidome is so abundant that even using the most modern mass spectrometers cannot be fully analyzed and thus, becomes "noise" that hinders the identification of the additional minority fraction of viral peptides generated in the infection. The acid stripping treatment removes all HLA-bound cell peptides on the cell surface [11]. In infected cells, only the peptides generated by proteolytic degradation of the fraction of newly synthesized viral or self-proteins whose sequence or folding are in some way defective (defective ribosomal products; DRiP) will be translocated to Endoplasmic Reticulum to be complexed with HLA class I molecules. Thus, this relative enrichment in pathogen ligands in addition to the viral hijacking of cell metabolism [13] allow the identification of additional VACV ligands bound to HLA as we demonstrated in the current study.

Although most VACV HLA-B*27:05 ligands were identified in both conditions, a significant fraction of viral peptides was exclusive, either in the untreated or the acid stripping treatment. The self-derived HLA peptidome from both conditions is different since the stripping acid treatment causes strong cellular stress to replace all lost surface proteins, modifying the normal balance of protein synthesis. In addition, the mass spectrometers only resolve the most abundant species in each point of the HPLC gradient and thus, the relative abundance of viral peptides versus self-peptides could explain the differences in the identification of virus ligands. Collectively, the data of our study indicate that, far from replacing the established protocol (since a similar number of VACV ligands is obtained to those published in previous studies [14-17]), the acid stripping treatment becomes a complementary method to increase the identification of viral ligands that, as experiments in the transgenic mice model have shown, are similarly antigenic to those obtained without the aforementioned treatment. Moreover, a similar number of mass spectrometry ligands identified untreated and after acid stripping condition VACV-infected cells were not recognized in the HLA-B*2705 transgenic mice. This absence of recognition is probably due to the 65 million years of evolutionary divergence between mice and humans, with accumulation of multiple differences in immune system development, activation, and response, in both innate and adaptive immunity [18]. These differences including relevant proteins involved in the antigen processing and presentation pathway as TAP [19] and endoplasmic reticulum-resident aminopeptidases [6,7].

An interesting fact, not strictly related to the objective of this study, was that four viral ligands (identified both in untreated and acid stripping VACV-infected cells) showed weak or no theoretical binding affinity for the HLA-B*27:05 class I molecule. The first was the SQFDDKGNTAL peptide, which was predicted by the bioinformatics tool as a low affinity ligand. This 11-mer peptide had Gln at P2 residue, an anchor motif shared with $3 \%$ of natural HLA-B*27:05 ligands [20-22]. The HLA-B*27:05 peptides with Gln as an alternative anchor motif presented experimental affinity values in the range commonly observed among natural ligands with the classical Arg at P2 anchor motif for HLA-B*27:05 binding [22]. In addition, AANRDNVASRLLN, FAANRDNVASRLLN, and PVIDRLPSETFPNVH peptides were not predicted as HLA-B*27:05 ligands by the bioinformatics tool. Although they seem to have no anchor motifs, AANRDNVASRLLN and FAANRDNVASRLLN ligands are N-extended peptides of the core NRDNVASRLLN, an 11-mer with the canonical anchor motif for HLA-B*27:05 binding. Similarly, PVIDRLPSETFPNVH 
peptide is the N-extension of the other canonical DRLPSETFPNVH peptide. The most likely explanation is that these peptides bind to HLA-B*27:05 with the canonical anchor motif at P2 in an N-extended conformation as others previously identified (SYFPEITHI database: http:/ / www.syfpeithi.de (accessed on May, 2021) [4]). These N-extended peptides can show a similar HLA binding affinity to short canonical peptides and, when they have a viral origin, could be highly antigenic and similarly abundant to minimal length epitopes [23]. Thus, it would be recommended to improve the performance of the HLA binding predictors with these non-canonical sequences obtained experimentally by mass spectrometry analysis.

\section{Materials and Methods}

\subsection{Cells, Antibodies and Synthetic Peptides}

B27-C1R is an HLA-B*27:05 transfectant [24] of the human lymphoid cell line HMy2.C1R. Cells were cultured in RPMI 1640 with $10 \%$ fetal bovine serum. The monoclonal antibody $(\mathrm{mAb})$ used in this study was W6/32 (specific for a monomorphic HLA class I) [25]. Peptides were synthesized by ProteoGenix (Schiltigheim, France).

\subsection{Mice}

HLA-B*2705 [26] transgenic mice were bred in our animal facilities in strict accordance with the recommendations of the Guide for the Care and Use of Laboratory Animals of the Spanish "Comisión Nacional de Bioseguridad" of the "Ministerio de Medio Ambiente y Medio Rural y Marino" (accreditation number 28079-34A). The protocol was approved by the Committee on Animal Experiment Ethics of the Institute of Health "Carlos III" (Permit Number: PI-283). All of the procedures were performed under sodium pentobarbital anesthesia, and all efforts were made to minimize suffering.

\subsection{Acid Stripping and HLA Class I Re-Expression}

Uninfected or VACV-infected cells after $2 \mathrm{~h}$ of infection (to allow entry of the virus) at moi 10 were washed with RPMI in the absence of serum and incubated for $90 \mathrm{~s}$ with ice-cool acid-stripping medium ( $0.3 \mathrm{M}$ glycine- $\mathrm{HCl}$ and $1 \% \mathrm{BSA}$ in water, $\mathrm{pH} 2.4)$ as previously reported [27]. Culture medium was added to neutralize the $\mathrm{pH}$. Cells were washed three times, resuspended in culture medium, and incubated at $37^{\circ} \mathrm{C}$ overnight to allow normal viral cycle and HLA class I re-expression.

\subsection{HLA Class I-Bound Peptide Isolation}

HLA-bound peptides were isolated from three independent biological replicates of $1 \times 10^{9}$ cells from uninfected or VACV-infected cells, treated or not with acid stripping after virus infection as previously described [28]. The VACV Western Reserve strain was utilized to infect $1 \times 10^{9} \mathrm{~B} 27-\mathrm{C} 1 \mathrm{R}$ cells at a multiplicity of infection of 10 plaque-forming units/cell in $100 \mathrm{~mL}$ for $2 \mathrm{~h}$ at $37^{\circ} \mathrm{C}$, and then cells were washed with PBS, as previously described [28]. These conditions were previously determined as the optimal to obtain infection of all cells without impairing the cell viability. Next, the cells were cultured for $4 \mathrm{~h}$ at $37^{\circ} \mathrm{C}$ and stained with the Omnitope antiserum-FITC that recognizes VACV virions (ViroStat Inc., Westbrook, ME, USA). Samples were analyzed measuring fluorescence intensity by flow cytometry to confirm VACV infection (1220 \pm 97 mean fluorescence intensity in VACV-infected cells versus $4222 \pm 38$ in non-infected cells stained with the anti-VACV antiserum). Cells were lysed in 1\% Igepal CA-630 (Merck KGaA, Darmstadt, Germany), $20 \mathrm{mM}$ Tris/ $\mathrm{HCl}$ buffer, and $150 \mathrm{mM} \mathrm{NaCl}, \mathrm{pH} 7.5$ in the presence of the Protease Inhibitor Cocktail (Merck KGaA, Darmstadt, Germany). After centrifugation, the supernatants were passed first through a control precolumn containing CNBr-activated Sepharose 4B (GE Healthcare, Buckinghamshire, UK) to remove non-specific proteins and peptides. The HLA-B*27:05/peptide complexes were isolated via affinity chromatography from the soluble cell extract fraction with the $\mathrm{W} 6 / 32 \mathrm{mAb}$. The HLA-bound peptides were eluted with $1 \%$ aqueous trifluoroacetic acid (TFA), separated from the HLA molecules, and 
concentrated by ultra-filtration with a Vivaspin 2 filter, 5000 MWCO HY (Sartorius Stedim Biotech, Goettingen, Germany), as previously described [29].

\subsection{LC-MS/MS Analysis}

Peptide samples were reconstituted in $6 \mu \mathrm{L}$ of $0.2 \%$ formic acid. $5 \mu \mathrm{L}$ of each fraction were analyzed by LC-MS/MS in a nano-LC Ultra HPLC (Eksigent, SCIEX, Framingham, MA, USA) coupled online with a 5600 triple TOF mass spectrometer (Sciex) through a Nanospray 3 ion source (SCIEX). The ion source was equipped with a PicoTip emitter $(10 \mu \mathrm{m} \times 12 \mathrm{~cm}$, New Objective, Woburn, MA, USA). The HPLC setup included an Acclaim PepMapTM 100 trapping column $(10 \mu \mathrm{m} \times 2 \mathrm{~cm}$, Thermo Fisher Scientific, Waltham, MA, USA) and a C18 Peptide BEH column (130 $, 1,7 \mu \mathrm{m} \times 150 \mathrm{~mm}$, Waters. Milford, MA, USA). Solvent $\mathrm{A}$ and $\mathrm{B}$ were $0.1 \%$ formic acid in water and acetonitrile, respectively. Peptides were separated at a flow-rate of $250 \mathrm{~nL} / \mathrm{min}$ at $50{ }^{\circ} \mathrm{C}$ under gradient elution conditions as follows: a linear increase from $5 \%$ to $30 \% \mathrm{~B}$ in $180 \mathrm{~min}$, a linear increase to $60 \% \mathrm{~B}$ in $20 \mathrm{~min}$, a linear increase to $90 \% \mathrm{~B}$ in $10 \mathrm{~min}, 90 \%$ B for $10 \mathrm{~min}$, a linear decrease to $5 \%$ B in $5 \mathrm{~min}$ and $5 \%$ B for $20 \mathrm{~min}$. Total run time was $250 \mathrm{~min}$. Each acquisition cycle included a survey scan of $250 \mathrm{~ms}$ between 350 and $1250 \mathrm{~m} / \mathrm{z}$ units and a maximum of 25 MS2 spectra scanning between 100 and $1500 \mathrm{~m} / \mathrm{z}$ units with an accumulation time of $100 \mathrm{~ms}$. The HPLC and the mass spectrometer were respectively controlled with the Eksigent Control (version 3.12, Eksigent) and the Analyst TF software (version 1.7, Eksigent).

\subsection{MS/MS Ion Search and Peptide Identification}

Raw MS/MS data were converted to mgf files with PeakView 1.2 (SCIEX) and searched with Peaks Studio X+". (Bioinformatics Solutions). The database (42,651 entries) contained the Human Reference Proteome and the Vaccinia (Western Reserve) Proteome downloaded from Uniprot in July 2019. The following parameters were used: no enzyme, MS tolerance of $25 \mathrm{ppm}, \mathrm{MS} / \mathrm{MS}$ tolerance of 0.05 and oxidation of $\mathrm{M}$ and pyroglutamic acid formation from $Q$ and $E$ as variable modifications. Identifications were filtered at a FDR $>1 \%$ at the peptide level. Similar amounts of uninfected human cells were used as a negative control to discriminate viral and cellular peptides (included in proteome databases as well as unknown peptides, whose parental proteins may not be included in current human databases) and to exclude erroneous assignments of viral peptides.

\subsection{In Silico Binding Prediction of HLA-B*27:05 Class I Ligands}

The predicted binding of each peptide to HLA-B*27:05 class I molecule was calculated using the artificial neural network-based alignment method NetMHCIpan EL4.1 (available in http:/ / www.cbs.dtu.dk/services/NetMHCpan/ (accessed on May, 2021)). Strong and weak theoretical affinity of ligands to HLA-B*27:05 corresponding to 1 and 5 percentile ranks were considered.

\subsection{IFN- $\gamma$-Secreting $C D 8^{+}$Cell Detection by ELISPOT}

ELISPOT assays were performed as previously described [30] to detect antigen-specific $\mathrm{CD} 8^{+} \mathrm{T}$ cell activation. Briefly, purified rat anti-mouse IFN- $\gamma$ antibody (clone R4-6A2, BD Pharmingen, San Diego, CA, USA) was coated on 96-well MultiScreen HTS HA plates (Millipore, Billerica, MA, USA). The plates were incubated overnight at room temperature and were blocked with medium that was supplemented with $10 \%$ fetal bovine serum for $2 \mathrm{~h}$ at $37^{\circ} \mathrm{C}$. Duplicate cultures of erythrocyte-depleted spleen cells were prepared from HLA class I-transgenic mice at 7 days (acute response) post intraperitoneal infection with $1 \times 10^{6} \mathrm{pfu}$ of VACV at different dilutions with $10^{-5} \mathrm{M}$ peptide. The plates were incubated overnight at $37^{\circ} \mathrm{C}$ in a $5 \% \mathrm{CO}_{2}$ atmosphere and were then washed with PBS$\mathrm{T}$ (PBS 0.05\% Tween-20). The plate wells were incubated for $2 \mathrm{~h}$ at room temperature with biotinylated anti-mouse IFN- $\gamma$ mAb clone XMG1.2 (BD Pharmingen), washed with PBS-T, and incubated for $1 \mathrm{~h}$ at room temperature with alkaline phosphatase-conjugated streptavidin (Sigma, St. Louis, MO, USA). The plates were additionally washed before 
adding the BCIP/NBT liquid substrate (Sigma, St. Louis, MO, USA). To enumerate the IFN $\gamma$ responses, spots were counted and wells were photographed using a Leica EZ4 HD stereo microscope and LAS EZ software (Leica Microsystems, Germany). Additionally, the percentage of $\mathrm{CD}^{+}$cells was determined after staining spleen cells with FITC-conjugated anti-mouse CD8 antibody (clone KT15, Proimmune, England, UK). Events were acquired on a FACSCanto flow cytometer (BD Biosciences, San Jose, CA, USA) and analyzed using BD FACSDiva software, version 6 (BD Bioscience). To analyze the statistical significance of the assays, a non-parametric Mann-Whitney $\mathrm{U}$ test was used. $p$ values $<0.05$ were considered to be statistically significant.

Author Contributions: Conceptualization, D.L.; methodology, E.L., M.M. and D.L.; formal analysis, E.L., M.M., P.G.d.1.S.; investigation, E.L., M.M., P.G.d.1.S., A.Q.-F. and C.M.; writing-original draft preparation, D.L.; writing-review and editing, E.L., M.M. and D.L.; supervision, D.L.; funding acquisition, D.L. All authors have read and agreed to the published version of the manuscript.

Funding: This work was supported by the Spanish Ministry of Science and Innovation SAF201458052 and "Acción Estratégica en Salud" MPY 388/18 to D.L.

Institutional Review Board Statement: The study was conducted according to the guidelines of the Declaration of Helsinki, and approved by the Institutional Review Board of the Instituto de Salud "Carlos III" (protocol code 28079-34A, September, 2019).

Data Availability Statement: Data are available via ProteomeXchange with identifier PXD027859.

Conflicts of Interest: The authors declare no conflict of interest. The funders had no role in the design of the study; in the collection, analyses, or interpretation of data; in the writing of the manuscript, or in the decision to publish the results.

\section{References}

1. Shastri, N.; Schwab, S.; Serwold, T. Producing nature's gene-chips: The generation of peptides for display by MHC class I molecules. Annu. Rev. Immunol. 2002, 20, 463-493. [CrossRef] [PubMed]

2. Bjorkman, P.J.; Saper, M.A.; Samraoui, B.; Bennett, W.S.; Strominger, J.L.; Wiley, D.C. Structure of the human class I histocompatibility antigen, HLA-A2. Nature 1987, 329, 506-512. [CrossRef]

3. Parker, K.C.; Bednarek, M.A.; Coligan, J.E. Scheme for ranking potential HLA-A2 binding peptides based on independent binding of individual peptide side-chains. J. Immunol. 1994, 152, 163-175. [PubMed]

4. Rammensee, H.G.; Bachmann, J.; Emmerich, N.P.N.; Bachor, O.A.; Stevanovic, S. SYFPEITHI: Database for MHC ligands and peptide motifs. Immunogenetics 1999, 50, 213-219. [CrossRef]

5. Saric, T.; Chang, S.C.; Hattori, A.; York, I.A.; Markant, S.; Rock, K.L.; Tsujimoto, M.; Goldberg, A.L. An IFN- $\gamma$-induced aminopeptidase in the ER, ERAP1, trims precursors to MHC class I-presented peptides. Nat. Immunol. 2002, 3, 1169-1176. [CrossRef] [PubMed]

6. Tanioka, T.; Hattori, A.; Masuda, S.; Nomura, Y.; Nakayama, H.; Mizutani, S.; Tsujimoto, M. Human leukocyte-derived arginine aminopeptidase-The third member of the oxytocinase subfamily of aminopeptidases. J. Biol. Chem. 2003, 278, 32275-32283. [CrossRef]

7. Hattori, A.; Matsumoto, H.; Mizutani, S.; Tsujimoto, M. Molecular cloning of adipocyte-derived leucine aminopeptidase highly related to placental leucine aminopeptidase/oxytocinase. J. Biochem. 1999, 125, 931-938. [CrossRef] [PubMed]

8. York, I.A.; Goldberg, A.L.; Mo, X.Y.; Rock, K.L. Proteolysis and class I major histocompatibility complex antigen presentation. Immunol. Rev. 1999, 172, 49-66. [CrossRef]

9. Ovsyannikova, I.G.; Johnson, K.L.; Bergen, H.R., III; Poland, G.A. Mass spectrometry and peptide-based vaccine development. Clin. Pharmacol. Ther. 2007, 82, 644-652. [CrossRef]

10. Le Bouteiller, P.P.; Mishal, Z.; Lemonnier, F.A.; Kourilsky, F.M. Quantification by flow cytofluorimetry of HLA class I molecules at the surface of murine cells transformed by cloned HLA genes. J. Immunol. Methods 1983, 61, 301-315. [CrossRef]

11. Vanderburg, S.H.; Ras, E.; Drijfhout, J.W.; Benckhuijsen, W.E.; Bremers, A.J.A.; Melief, C.J.M.; Kast, W.M. An HLA class I peptide-binding assay based on competition for binding to class I molecules on intact human B cells-Identification of conserved HIV-1 polymerase peptides binding to HLA-A*0301. Hum. Immunol. 1995, 44, 189-198. [CrossRef]

12. Schulze zur, W.J.; Lauer, G.M.; Day, C.L.; Kim, A.Y.; Ouchi, K.; Duncan, J.E.; Wurcel, A.G.; Timm, J.; Jones, A.M.; Mothe, B.; et al. Broad repertoire of the CD4+ Th cell response in spontaneously controlled hepatitis $\mathrm{C}$ virus infection includes dominant and highly promiscuous epitopes. J. Immunol. 2005, 175, 3603-3613. [CrossRef] [PubMed]

13. Thaker, S.K.; Chng, J.; Christofk, H.R. Viral hijacking of cellular metabolism. BMC Biol. 2019, 17, 59. [CrossRef] [PubMed] 
14. Ternette, N.; Block, P.D.; Sanchez-Bernabeu, A.; Borthwick, N.; Pappalardo, E.; Abdul-Jawad, S.; Ondondo, B.; Charles, P.D.; Dorrell, L.; Kessler, B.M.; et al. Early Kinetics of the HLA Class I-Associated Peptidome of MVA.HIVconsv-Infected Cells. J. Virol. 2015, 89, 5760-5771. [CrossRef]

15. Gilchuk, P.; Spencer, C.T.; Conant, S.B.; Hill, T.; Gray, J.J.; Niu, X.; Zheng, M.; Erickson, J.J.; Boyd, K.L.; McAfee, K.J.; et al. Discovering naturally processed antigenic determinants that confer protective T cell immunity. J. Clin. Investig. 2013, 123, 1976-1987. [CrossRef]

16. Johnson, K.L.; Ovsyannikova, I.G.; Mason, C.J.; Bergen, H.R., III; Poland, G.A. Discovery of naturally processed and HLApresented class I peptides from vaccinia virus infection using mass spectrometry for vaccine development. Vaccine 2009, $28,38-47$. [CrossRef]

17. Lorente, E.; Martin-Galiano, A.J.; Barnea, E.; Barriga, A.; Palomo, C.; Garcia-Arriaza, J.; Mir, C.; Lauzurica, P.; Esteban, M.; Admon, A.; et al. Proteomics analysis reveals that structural proteins of the virion core and involved in gene expression are the main source for HLA class II ligands in vaccinia virus-infected cells. J. Proteom. Res. 2019, 18, 900-911. [CrossRef]

18. Mestas, J.; Hughes, C.C. Of mice and not men: Differences between mouse and human immunology. J. Immunol. 2004, 172, 2731-2738. [CrossRef]

19. Neefjes, J.; Gottfried, E.; Roelse, J.; Grommé, M.; Obst, R.; Hämmerling, G.J.; Momburg, F. Analysis of the fine specificity of rat, mouse and human TAP peptide transporters. Eur. J. Immunol. 1995, 25, 1133-1136. [CrossRef]

20. Alvarez, I.; Sesma, L.; Marcilla, M.; Ramos, M.; Marti, M.; Camafeita, E.; de Castro, J.A. Identification of novel HLA-B27 ligands derived from polymorphic regions of its own or other class I molecules based on direct generation by $20 \mathrm{~S}$ proteasome. J. Biol. Chem. 2001, 276, 32729-32737. [CrossRef]

21. Ben Dror, L.; Barnea, E.; Beer, I.; Mann, M.; Admon, A. The HLA-B*2705 peptidome. Arthritis Rheum. 2010, 62, 420-429. [PubMed]

22. Infantes, S.; Lorente, E.; Barnea, E.; Beer, I.; Barriga, A.; Lasala, F.; Jimenez, M.; Admon, A.; Lopez, D. Natural HLA-B²705 protein ligands with glutamine as anchor motif: Implications for HLA-B27 association with spondyloarthropathy. J. Biol. Chem. 2013, 288, 10882-10889. [CrossRef] [PubMed]

23. Samino, Y.; López, D.; Guil, S.; Saveanu, L.; van Endert, P.M.; Del Val, M. A long N-terminal-extended nested set of abundant and antigenic major histocompatibility complex class I natural ligands from HIV envelope protein. J. Biol. Chem. 2006, 281, 6358-6365. [CrossRef] [PubMed]

24. Calvo, V.; Rojo, S.; López, D.; Galocha, B.; Lopez de Castro, J.A. Structure and diversity of HLA-B27-specific T cell epitopes. Analysis with site-directed mutants mimicking HLA-B27 subtype polymorphism. J. Immunol. 1990, 144, 4038-4045.

25. Barnstable, C.J.; Bodmer, W.F.; Brown, G.; Galfre, G.; Milstein, C.; Williams, A.F.; Ziegler, A. Production of monoclonal antibodies to group A erythrocytes, HLA and other human cell surface antigens-new tools for genetic analysis. Cell 1978, 14, 9-20. [CrossRef]

26. Khare, S.D.; Luthra, H.S.; David, C.S. Spontaneous inflammatory arthritis in HLA-B27 transgenic mice lacking beta 2-microglobulin: A model of human spondyloarthropathies. J. Exp. Med. 1995, 182, 1153-1158. [CrossRef]

27. Luckey, C.J.; Marto, J.A.; Partridge, M.; Hall, E.; White, F.M.; Lippolis, J.D.; Shabanowitz, J.; Hunt, D.F.; Engelhard, V.H. Differences in the expression of human class I MHC alleles and their associated peptides in the presence of proteasome inhibitors. J. Immunol. 2001, 167, 1212-1221. [CrossRef]

28. Infantes, S.; Lorente, E.; Barnea, E.; Beer, I.; Cragnolini, J.J.; García, R.; Lasala, F.; Jiménez, M.; Admon, A.; López, D. Multiple, non-conserved, internal viral ligands naturally presented by HLA-B27 in human respiratory syncytial virus-infected cells. Mol. Cell. Proteom. 2010, 9, 1533-1539. [CrossRef]

29. Johnstone, C.; Lorente, E.; Barriga, A.; Barnea, E.; Infantes, S.; Lemonnier, F.A.; David, C.S.; Admon, A.; Lopez, D. The Viral Transcription Group Determines the HLA Class I Cellular Immune Response Against Human Respiratory Syncytial Virus. Mol. Cell Proteom. 2015, 14, 893-904. [CrossRef]

30. Tapia, E.; Perez-Jimenez, E.; Lopez-Fuertes, L.; Gonzalo, R.; Gherardi, M.M.; Esteban, M. The combination of DNA vectors expressing IL-12 + IL-18 elicits high protective immune response against cutaneous leishmaniasis after priming with DNAp36/LACK and the cytokines, followed by a booster with a vaccinia virus recombinant expressing p36/LACK. Microbes Infect. 2003, 5, 73-84. [CrossRef] 